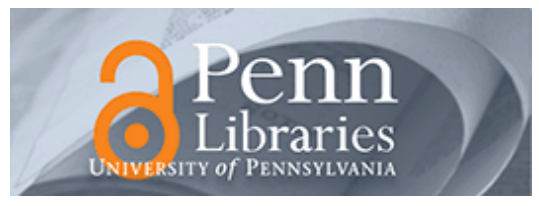

University of Pennsylvania

ScholarlyCommons

Management Papers

Wharton Faculty Research

2-2008

\title{
When Better Is Worse: Envy and the Use of Deception
}

\author{
Simone Moran
}

Maurice E. Schweitzer

University of Pennsylvania

Follow this and additional works at: https://repository.upenn.edu/mgmt_papers

Part of the Business Administration, Management, and Operations Commons, Business Intelligence Commons, Cognition and Perception Commons, Cognitive Psychology Commons, Experimental Analysis of Behavior Commons, Management Sciences and Quantitative Methods Commons, Personality and Social Contexts Commons, and the Social Psychology Commons

\section{Recommended Citation}

Moran, S., \& Schweitzer, M. E. (2008). When Better Is Worse: Envy and the Use of Deception. Negotiation and Conflict Management Research, 1 (1), 3-29. http://dx.doi.org/10.1111/j.1750-4716.2007.00002.x

This paper is posted at ScholarlyCommons. https://repository.upenn.edu/mgmt_papers/316

For more information, please contact repository@pobox.upenn.edu. 


\title{
When Better Is Worse: Envy and the Use of Deception
}

\author{
Abstract \\ In this article, we describe how envy motivates deception. We find that individuals who envy a counterpart \\ are more likely to deceive them than are individuals who do not envy their counterpart. Across both a \\ scenario and a laboratory study, we explore the influence of envy in a negotiation setting. Negotiations \\ represent a domain in which social comparisons are prevalent and deception poses a particularly \\ important concern. In our studies, we induce envy by providing participants with upward social \\ comparison information. We find that upward social comparisons predictably trigger envy, and that envy \\ promotes deception by increasing psychological benefits and decreasing psychological costs of \\ engaging in deceptive behavior. We discuss implications of our results with respect to negotiations and \\ the role of emotions in ethical decision making.

\section{Keywords} \\ negotiations, emotion, ethics, deception, envy, social comparison \\ Disciplines \\ Business Administration, Management, and Operations | Business Intelligence | Cognition and Perception \\ | Cognitive Psychology | Experimental Analysis of Behavior | Management Sciences and Quantitative \\ Methods | Personality and Social Contexts | Social Psychology
}




\title{
When Better is Worse:
}

\section{Envy and the Use of Deception in Negotiations}

\author{
Simone Moran \\ Ben Gurion University \\ School of Management \\ PO Box 653, Beer Sheva 84105, Israel \\ Phone/Fax: 972-8-647-9802/7697 \\ Email: simone@bgu.ac.il \\ Maurice E. Schweitzer \\ University of Pennsylvania \\ 3730 Walnut Street \\ Philadelphia, PA 19104 \\ Phone/Fax: 215-898-4776/3664 \\ E-mail: Schweitzer@wharton.upenn.edu
}

Draft version, August 17, 2005.

This manuscript has not been peer reviewed.

Please do not copy or cite without author's permission

We thank Ofer Tal, Michal Sharon, Liron Levkowitz, Gilat Alon, Lior Peer, Dafna Shamir, Michal Meyuhas, and Roni Laslow for research assistance, and the University Research Foundation at the University of Pennsylvania for financial support. 


\title{
When Better is Worse:
}

\section{Envy and the Use of Deception in Negotiations}

\begin{abstract}
In this paper we describe the influence of envy on the use of deception. We find that individuals who envy a counterpart are more likely to deceive them than are individuals who do not envy their counterpart. Across both a scenario and a laboratory study, we explore the influence of envy in a negotiation setting. Negotiations represent a domain in which social comparisons are prevalent and deception poses a particularly important concern. In our studies, we induce envy by providing participants with upward social comparison information. We find that upward social comparisons predictably trigger envy, and that envy promotes deception by increasing perceived gains and decreasing psychological costs of engaging in deceptive behavior. We discuss implications of our results with respect to impression management and emotional intelligence as well as the role of emotions in ethical decision making and negotiations.
\end{abstract}

Keywords: deception, envy, negotiations, emotions, social comparison, ethics 
Recent research has made important strides in understanding an important, but often neglected emotion, envy. Although envy is a self-sanctioned emotion that is not often vocalized, it is frequently a strong emotional reaction to an unfavorable social comparison and prior work has found that envy can exert substantial influence on interpersonal attitudes and behavior (e.g., Feather, 1989, 1991; Parrott \& Smith, 1993; Salovey \& Rodin, 1984; Smith, 1991; Smith et al., 1994; Smith et al.,1996; Smith et al., 1999; Tesser \& Collins, 1988; Vecchio, 1995, 2000).

Surprisingly little research has considered the role of envy in organizational settings (see Mouly \& Sunkaran, 2002; Vecchio, 1995, 2000 for exceptions). We postulate that envy is likely to play a particularly important role in organizations that both induce envy by promoting social comparisons (e.g., via performance reviews or promotion decisions) and require coordination among employees. In the present research, we consider an organizational domain in which envy is particularly likely to be triggered and in which envy is likely to have profound consequences, negotiations. Specifically, we explore the influence of envy in motivating a negotiator's use of deception.

\section{ENVY}

Envy is defined as "the feelings that arouse when one person desires to have something that another person possesses" (Silver and Sabini, 1978. p. 107). Envy is often evoked when individuals are outperformed in a domain relevant to their self-concept, and prior work has found that envy is often associated with feelings of inferiority, frustration, subjective injustice, and longing (Parrott \& Smith, 1993). In general, feelings of envy are more intense when the outperformer is someone similar to the target individual and when the outperformed person has suffered a setback (Salovey \& Rodin, 1984; Tesser \& Collins, 1988; Heider, 1958; Smith et al., 1996; Smith et al., 1999).

A number of studies suggest that envy may have important negative interpersonal consequences. Prior work has shown envy to shift attitudes and feelings toward the envied person 
in several ways. People experiencing envy tend to devalue and belittle the envied target (Salovey \& Rodin, 1984; Vecchio, 1995). For example, Salovey and Rodin (1984) found that participants rate students whom they envy lower than other students on traits such as caring, niceness, and attractiveness. Envy has also been associated with feelings of hostility (Smith, Parrott, Ozer \& Moniz, 1994) and with schadenfreude (taking pleasure in the suffering of others; Smith et al., 1996; Brigham, Kelso, Jackson \& Smith, 1997). These findings are consistent with the "tall poppy" syndrome documented by Feather $(1989,1991)$ in Australian culture. This syndrome describes the tendency of individuals to hold negative attitudes toward successful others ("tall poppies"), and to favor their fall. Envy has been shown to have an impact not only on attitudes and feelings but also on behavioral tendencies and choices in interpersonal contexts. For example, envy has been associated with lower cooperation rates in social dilemmas (Parks, Rumble \& Posey, 2002) and with increased social loafing and lower levels of group performance (Duffy and Shaw, 2000). In the present work, we extend this line of research by exploring the role of envy in promoting deception. We focus on negotiations, a domain where social comparisons are prevalent and deception possesses a particularly important concern.

\section{ENVY AND NEGOTIATIONS}

Negotiations are common social interactions frequently used by people to resolve differences and allocate resources. Negotiations occur at many levels, between buyers and sellers, politicians and diplomats, spouses, friends, colleagues, etc. (Bazerman and Neale, 1992).

Prior work has demonstrated that social comparisons are common within negotiations (Connolly \& Ordonez, 2000; Loewenstein, Thompson \& Bazerman, 1989; Novemsky \& Schweitzer, 2004). Since envy is triggered by social comparisons, we expect envy to be prevalent in negotiation settings. Although negotiators are likely to engage in social comparisons with their counterparts before, during, and after a negotiation, previous research has primarily focused on the influence of social comparisons with respect to outcomes after a negotiation has been 
completed. No prior work has considered how ex-ante comparisons might impact negotiator behavior. In this paper, we investigate this issue and describe the influence of envy produced by unfavorable pre-negotiation social comparisons on an important negotiator behavior, the use of deception.

A growing body of negotiation research also explores the impact of affect in negotiations (for reviews see Thompson, Nadler \& Kim, 1999; Bazerman, Curhan, Moore \& Valley, 2000; Barry \& Oliver, 1996). Much of this work has contrasted the influence of positive and negative moods. This work has found that individuals experiencing positive, rather than negative affect are more likely to engage in cooperative behavior, less likely to engage in contentious behavior, and more likely to create joint value (e.g., Carnevale \& Isen, 1986; Isen, Daubman \& Nowicki, 1987; Baron, 1990; Forgas, 1998; Murnighan, 1991). Related work has begun to focus on the influence of discrete emotions in negotiation, especially anger. This work has found that anger reduces joint gains, decreases the desire of negotiators to work together in the future, intensifies competitive behavior, and increases the rejection rate of offers (e.g., Allred, Mallozzi, Matsui, \& Raia, 1997; Pillutla \& Murnighan, 1996). In some cases, however, the expression of negative emotions such as anger in negotiation can serve important communicative functions that benefit negotiators (Thompson et al., 1999; Frank 1988; Friedman et al., 2004; Van Kleef, De Dreu \& Manstead, 2004a,b; Morris \& Keltner, 2000). For example, Van Kleef et al., (2004a,b) demonstrate that expressing anger can elicit concessions from a counterpart.

Little negotiation research, however, has considered the influence of discrete emotions other than anger. As already noted, envy is one of the strongest emotions evoked by unfavorable social comparisons (Salovey \& Rodin, 1984; Smith et al., 1999; Tesser \& Collins, 1988). Given the extant literature describing the important role that social comparisons play in interpersonal contexts such as negotiations (Connolly \& Ordonez, 2000; Loewenstein et al., 1989; Novemsky \& Schweitzer, 2004), the lack of prior work studying the role of envy in negotiations is surprising. 


\section{DECEPTION IN NEGOTIATIONS}

Deception represents a particularly important issue in negotiations (Lewicki, Barry, Saunders \& Minton, 2003). Negotiations are characterized by information dependence; negotiators typically posses private information, which they need to share to reach an efficient agreement. In many cases, however, negotiators can misrepresent their private information to gain power and an opportunistic advantage (Lewicki et al., 2003; Robinson, Lewicki, \& Donahue, 2000; Schweitzer \& Croson, 1999).

Models of ethical decision making have largely neglected the role of emotion. Prior models have conceptualized ethical decision making as a product of economic incentives (Alingham \& Sandmo, 1972; Holmstrom, 1979) or a mixture of incentives and cognitive factors (Jones, 1995; Jones \& Ryan, 1997, 2001; Lewicki, Saunders \& Minton, 1999; Lewicki, 1983; Lewicki et el., 2003; Trevino, 1986; Grover, 1993; Tenbrunsel \& Messick, 2001, 2004; Gneezy, 2004; Alingham \& Sandmo, 1972; Schweitzer, Ordonez \& Douma, 2004). For example, Lewicki (Lewicki, 1983; Lewicki et el., 2003) suggests that individuals make unethical decisions by weighing the perceived benefits and perceived costs of engaging in unethical acts.

A few studies have considered emotional responses to unethical behavior. For example, Gaudine and Thorne (2001) suggest that emotional reactions may help decision makers identify ethical dilemmas, and in fact, research has found that emotional expressions do facilitate deception detection (e.g., Frank, 1988, 2002; Ekman, 2003; Buller \& Burgoon, 1998; Frank \& Ekman, 1997). Related work has considered the possibility that individuals might strategically misrepresent their emotions (Barry, 1999). This research, however, has not considered how emotions might operate as an antecedent of the decision to use deception.

In the present work, we test the thesis that discrete feelings of envy increase the likelihood that an individual will engage in deception. Drawing upon previous findings we suggest that envy is likely promote deception by increasing the psychological gains and decreasing the 
psychological costs of using deception when interacting with an envied counterpart. Congruent with the above mentioned research that has linked envy with schadenfreude (taking pleasure in the suffering of others; Smith et al., 1996, Feather, 1989, 1991), we postulate that feelings of envy may increase an individual's perceived psychological benefit from harming a counterpart via deception. Our notion that envy might lower the perceived psychological cost of engaging in deception is based on the previously described work that has found people experiencing envy to devalue and belittle the envied target (Salovey \& Rodin, 1984; Vecchio, 1995). We maintain that deceiving is likely to entail lower psychological costs and be easier to self justify if the person we deceive is devalued and belittled. To recapitulate this argument, envy that enhances belittling is expected to promote deception, since deceiving a belittled person may be easier to self-justify, and thereby entail lower psychological costs (Lewicki et al., 2003; Schweitzer \& Hsee, 2002).

We conducted two studies to test the thesis that envy promotes deception. The first study employs scenario methods and explores the mechanics of the relationship between envy and deception. The second study examines actual behavior in a setting with monetary stakes.

\section{STUDY 1}

In this study, we examine the relationship between envy and intentions to engage in deception. We induce envy by describing different relative outcomes, and explore the mechanics of the relationship between envy and deception within a negotiation context. In particular, we describe the role of envy in promoting schadenfreude, thereby increasing psychological gains of deceiving, and in belittling the other person, thereby assisting self- justification and lowering the psychological costs of engaging in deception. 


\section{Method}

\section{Design}

Participants completed one of four versions of a survey from a $2 \times 2$ between subject design which included two envy conditions (high or low) and two gender conditions (male or female). In both envy conditions, participants were asked to imagine a scenario at work in which they competed for and did not win a desired promotion. Participants were then asked to consider engaging in a negotiation with either the person who was awarded the promotion (high envy condition) or another person who was not awarded the promotion (low envy condition).

Across conditions, we attempted to control for a number of factors. First, across conditions participants were asked to imagine being involved in a competition. Second, across conditions participants are asked to imagine losing. Third, across conditions we attempted to control for perceptions of procedural fairness. We described the company and its typical management decision making procedures in the following way: "You like the company, and believe that senior management goes to great lengths to make decisions carefully and fairly." This was done to control for the possibility that subjective beliefs of injustice underlie the link between feelings of envy and deception (see Smith et al., 1994).

Prior work has found that envy is experienced most acutely when individuals consider target others who are similar to themselves. Consequently, we matched the gender of the hypothetical counterpart with that of the respondent, so that male participants read a scenario about males and females about females. We further facilitated similarity beliefs by describing the participant and counterpart as having the same "career track", with similar interests and goals for advancement in the company.

\section{Participants}

We recruited 164 participants to complete a survey in exchange for a chocolate bar. These participants included 47 working professionals and 115 MBA and Executive MBA students. A 
majority of the participants (105) were female. On average, participants were 33 years old $(\mathrm{sd}=8.6)$, and had worked for 7.9 years $(\mathrm{sd}=8)$. Within each participant group and across both genders, we randomly assigned participants to one of the two envy conditions. Overall, 83 participants completed the high envy version and 81 completed the low envy version.

\section{Procedure and Materials}

In each condition, participants received a package of materials. The first part included the scenario describing the competition, its outcome, and the upcoming negotiation. The second part included an eight-item measure of deception. The third part measured envy. The fourth part measured perceived procedural fairness and assessed potential mediators of the relationship between envy and deception, including perceived psychological gains and psychological costs of engaging in deception. The final part solicited demographic information.

\section{Scenario}

Participants were asked to imagine competing with four co-workers for a desirable promotion. They were asked to imagine that after putting in long hours to increase their chance of earning the promotion, they learned from senior management that they were ranked second and were not selected. The promotion takes effect in one month, and before it takes effect, participants were told that they will need to work on a new company project with one of the co-workers with whom they competed for the promotion. This co-worker was either selected for the promotion (ranked first) or not selected for the promotion (ranked third). Participants were given details about the new project and told that as a first step, they "will need to negotiate the structure of this new project."

\section{Deception measure}

Immediately after reading the scenario, participants completed an eight-item measure of unethical behavior that we adapted from the SINS scale (Self-reported Inappropriate Negotiation Strategies; Robinson, Lewicki, \& Donahue, 2000). We chose and adapted items from the SINS 
scale to match our negotiation context, and we list the items we used in Appendix 1. The scale reliability (Cronbach's $\alpha$ ) for the eight items was .83 , and we used their mean as a combined measure for subsequent analysis.

\section{Envy measure}

Our envy measure included four items. The first item directly asked participants to rate on a seven point scale the degree to which they felt envy toward their negotiating partner. The additional three items asked participants to rate the degree to which they agreed with the following statements about their negotiating partner: "Her/his outcome (winning/not winning the promotion) has many advantages"; "I would have very much liked to get her/his outcome"; "The thought of her/his outcome makes me feel aggravated." We computed the mean of these four items as our multi-item measure of envy (Cronbach's $\alpha=.89$ ) and report results with respect to this measure. (We conducted a separate set of analyses using the single item envy measure, and obtained the same pattern of results.)

\section{Potential Mediators}

We also included questions to measure potential mediators of the relationship between envy and deception (we list the items in Appendix 2). These included: (a) five items for assessing belittling and self-justification of deception - i.e., psychological cost of deception, and (b) three items for assessing feelings of schadenfreude toward the other party - i.e., psychological gains of deception. The Cronbach's $\alpha$ for the five psychological cost items is .66, and we used their mean score as an aggregate measure of perceived costs and justification. The three schadenfreude items measure potential psychological benefits of engaging in deception. The Cronbach's $\alpha$ for these three items was only .45 , but increased to .57 when we excluded the first item. Hence, we computed an aggregate mean schadenfreude measure without including the first item. 


\section{Procedural fairness}

We assessed perceived procedural fairness with two items. The first referred to the specific current promotion decision: "I believe this promotion decision was made fairly." and the second referred to the general company decision making procedures: "The procedures this company uses for making promotion decisions are typically unfair.” $(\mathrm{r}=.31, \mathrm{p}<.05)$.

\section{Demographic measures.}

We asked participants demographic questions about their age, gender, and years of work experience.

\section{Results}

We first conducted a manipulation check. In an ANOVA testing envy ratings as a function of the envy condition and gender, the envy condition was significant $\left(\mathrm{F}_{1,160}=478.95, \mathrm{p}<.0001\right.$, $\eta^{2}=.75$ ), but neither gender nor the interaction were significant ( $p$ 's $>.5$ ). That is, across both men and women, mean envy scores were significantly higher in the high envy condition, 5.60 $(\mathrm{sd}=0.9)$, than they were in the low envy condition, $2.04(\mathrm{sd}=1.04)$.

Although envy can be exacerbated by perceptions of unfairness (Smith et al., 1994), we attempted to control for perceptions of fairness through our description of the company's decision processes. We assessed the effectiveness of this control by examining participants' responses to each of the two perceived procedural fairness items (one referred to the particular promotion decision, and the other to the company decisions in general) as a function of the experimental condition. Across conditions, none of these perceptions of procedural fairness were significantly different ( $t^{\prime} s<1, p^{\prime} s>3$, for both items), suggesting that in manipulating envy we did not significantly influence perceptions of procedural fairness.

We next examined the tendency to engage in deception as a function of condition and gender. We conducted a factorial ANOVA with SINS score as the dependent variable and 
condition (high or low envy) and gender (male or female) as independent variables. We depict these results in Figure 1. As expected, we find a significant main effect for condition $\left(\mathrm{F}_{1,160}=5.53\right.$, $\mathrm{p}<.05, \eta^{2}=.03$ ); participants in the high envy condition claimed that they were more likely to engage in deception than were participants in the low envy condition . Consistent with previous findings (e.g., Lewicki \& Robinson, 1998; Robinson, Lewicki, \& Donahue, 2000), we also found a significant main effect for gender $\left(\mathrm{F}_{1,160}=4.47, \mathrm{p}<.05, \eta^{2}=.03\right)$; males reported a greater willingness to engage in deception than did females. We did not, however, find a significant interaction between gender and condition $\left(\mathrm{F}_{1,160}=.03, \mathrm{p}=.85\right)$, suggesting that envy increased the self-reported likelihood that men and women would engage in deception by roughly the same amount.

We continued to examine our main thesis that envy enhances the likelihood of engaging in deception, and that this link is mediated by perceived psychological costs and benefits of deceiving. First, in Table 1, we present the raw correlations between the three independent variables: feelings of envy, psychological costs and psychological gains (schadenfreude). We continue to conduct mediation analyses (Baron \& Kenny, 1986) to explore the relationships between feelings of envy, perceived psychological benefits and costs of deception, and intentions to use deception. Results of this analysis are depicted in Figure 2. As shown in the figure, we find that both psychological benefits (schadenfreude) and psychological costs shift as a function of envy and that these changes mediate the relationship between envy and deception. First, envy significantly affects schadenfreude as well as perceived psychological costs. Second, envy significantly affects intentions to engage in deception (absent other predictors). Third, a multiple regression for predicting the SINS score from envy in addition to schadenfreude and perceived costs reveals that both schadenfreude and perceived costs have a significant unique effect, and that when adding them to the model, the effect of envy decreases and becomes insignificant (see results of this multiple regression in Table 2, which also shows that collinearity is not a concern in 
this study). This pattern of results implies that both perceived psychological costs and schadenfreude play a mediating role in the effect of envy on intended deception. We also conducted two separate Sobel tests for each mediator (Sobel, 1982). Results from the Sobel tests identify both perceived costs $(\mathrm{z}=2.85, \mathrm{p}<.01)$ and schadenfreude $(\mathrm{z}=3.09, \mathrm{p}<.01)$ as significant mediators. ${ }^{1}$

\section{Study 1 Discussion}

We find that feelings of envy increase the self-reported likelihood of engaging in deception during a negotiation. While prior work has found that unfavorable relative outcomes can harm negotiator satisfaction following a negotiation (e.g., Novemsky \& Schweitzer, 2004), these results suggest that unfavorable relative outcomes prior to a negotiation influence negotiator behavior.

We find that envy promotes deception in two ways. First, envy increases the psychological benefits from using deception by inducing schadenfreude, Second, envy lowers the perceived costs of deceiving by facilitating belittling and self justification. This cost-benefit framework is consistent with Lewicki's model of deception (Lewicki 1983; Lewicki et el., 2003), which postulates that individuals make unethical decisions by weighing the perceived benefits and perceived costs of engaging in unethical acts.

Results from our study also offer insight into the mechanics of envy. Notably, they demonstrate that envy in an organizational context is easily aroused. In addition, while prior work has suggested that perceptions of unfairness are an important part of feeling envy, our results suggest that perceived unfairness is not necessary for envy to operate.

\section{STUDY 2}

\footnotetext{
${ }^{1}$ We conducted two additional hierarchical regression analyses, alternating the order of entering psychological benefits and costs as independent predictors of SINS (envy always included first). For reasons of simplicity we do not report results in detail. However, we note that both models replicated our above reported mediation analysis. Independent of their order in the model, both psychological costs and psychological benefits (schadenfreude) had significantly unique contributions to predicting intended deception.
} 
In Study 2, we extended our investigation of the relationship between envy and deception. Rather than manipulating envy by describing discrete unfavorable outcomes from a competition, as in Study 1, we manipulated envy by providing general unfavorable social comparison information. In this study, we also used a behavioral measure of deception with monetary stakes.

The primary dependent variable in this study was claims participants made within a negotiation context. We asked participants to make decisions as "Proposers" in a single-period Ultimatum game with an uncertain pie size. In a typical Ultimatum game, two people decide how to split a sum of money. A "Proposer" proposes a split of a sum of money, and a "Responder" can either accept or reject the proposed division. If the Responder rejects the division, both players receive no money. If the Responder accepts the division, both players receive the amounts indicated by the proposal (e.g., Guth, Schmittberger, \& Schwartze, 1982; Thaler, 1988).

In the uncertain pie size version of the Ultimatum game, Responders do not know the size of the initial sum of money (or "pie”). Instead, Responders learn about the amount they are offered and receive either no information or a limited amount of information about the initial sum (e.g., Croson, Boles \& Murnighan, 2003; Straub \& Murnighan, 1995).

In our study, participants could lie about the size of the pie when making an offer to their counterpart (the Responder). We randomly assigned participants to one of two envy conditions by manipulating social comparison information. We tested the thesis that when people are paired with a highly successful counterpart they will be more likely to envy their counterpart and to lie to their counterpart than when they are paired with a moderately successful counterpart.

Pilot Test of the Envy Manipulation

Method

\section{Design}


We first conducted a pilot study to gauge the effectiveness of our envy manipulation. We used a $2 \times 2$ between-subject design that included two envy conditions (high versus low) and two gender conditions (male versus female). Both male and female participants read about a samegender counterpart who was either highly successful or moderately successful.

\section{Participants}

We recruited a total of 46 participants, 30 males and 16 females. We recruited participants via poster advertisements at an Israeli university with an offer to pay participants 25 NIS (approximately \$5 USD) for their participation.

Procedure

As participants arrived, an experimenter assigned each individual to one of two adjacent rooms. The experimenters made an effort to convince participants that two parallel sessions of the experiment would transpire. These efforts included the following: First, the experimental rooms were located next to each other so that participants could see other participants entering a neighboring room. Second, before the experiment began, the experimenters counted the number of participants several times, made short announcements apologizing for the slight delay and explained that before beginning the experiment it is essential for both rooms to have an equal number of participants. Third, at the start of the experiment, participants read and heard the experimenter read aloud the following instructions:

You and another group of students, currently located in a classroom nearby, are about to participate in a career assessment study. You will be asked to write a short description of yourself (by answering a few focused questions) and to complete personality measures. After writing the description and completing the personality measures, you will be paired with someone from the other room. You will read their essay and assess their career prospects. 
Participants then completed a short "background information" survey that asked participants several questions about their background, including demographic questions, questions about their academic performance, entrance examination scores, military experience (which is compulsive in Israel), and social life.

Research assistants collected the completed surveys, presumably to exchange them with participants in the other classroom, and gave participants a personality survey that included items from various scales. This served as a filler task to allow experimenters time to prepare (outside of view) the next set of materials.

After participants completed the filler task, research assistants distributed completed versions of the background information survey. During this stage of the experiment, participants were led to believe that they would receive answers to the background information survey provided by a fellow participant in the neighboring room. In fact, each participant received one of four versions of the background information survey. These versions were handwritten and prepopulated to induce either high or low amounts of envy. We created the four versions from a $2 \times 2$ design that matched each participant's gender and included a description of either a high performer or an average performer.

While participants completed the filler task (the personality questionnaires), experimenters outside the lab randomly assigned each participant to an envy condition, matched the gender of that participant, and tailored the induction materials by matching information for the age and academic major of the pre-populated counterpart's background information. Through this matching process, each participant read a completed background information survey about someone who was identical to them in terms of gender, age, and academic major, but was either a high performer or an average performer. We matched participants along these demographic dimensions to increase the self-relevance of the comparison.

Consistent with the purported objective of the experiment, we asked participants to assess 
the future career success of their "partner". We then assessed their feelings of envy toward this partner. We adapted the four item envy measure we used in Study 1 to match the current context. In addition to the direct envy item, the measure included the following three items: "This student has a highly advantageous and desirable resume"; "I would very much like to have a resume similar to this student's resume", "The thought of her/his accomplishments makes me feel aggravated.". Cronbach's $\alpha$ measure for these items was 0.80 , and we consequently used their mean as an aggregated measure of envy.

At the end of the experiment, participants were debriefed and paid for participation. Experimenters explained the importance of initially concealing the true purpose of the study, and of using the different versions of the background information. Experimenters thanked participants and provided contact information to enable further inquiries about the experiment.

\section{Results and Discussion}

We first conducted a factorial ANOVA on the mean envy score as a function of the envy condition and gender. Results from this ANOVA revealed that the envy manipulation was, as expected, effective. Feelings of envy were significantly higher in the high envy condition than they were in the low envy condition, $4.2(\mathrm{sd}=1.2)$ versus $2.5(\mathrm{sd}=0.8)$ respectively, $\mathrm{F}_{1,42}=35.5$, $\mathrm{p}<.0001, \eta^{2}=0.46$. We found no significant main or interaction effects for gender. On average, men reported envy at levels very similar to those of women, $3.36(\mathrm{sd}=1.3)$ versus $3.33(\mathrm{sd}=1.4)$ respectively, $\mathrm{F}_{1,42}=0.25, \mathrm{p}=.6, \eta^{2}=.006$.

In this pilot study, we identified a method for inducing feelings of envy toward a potential counterpart. Across both genders, we found that participants reported significantly higher amounts of envy after reading about a high achieving counterpart than they did after reading about a moderately successful counterpart. 


\section{Lab Experiment}

\section{Method}

\section{Design}

As in the pilot study, we used a $2 \times 2$ between-subject design that included two envy conditions (high versus low) and two gender conditions (male versus female).

\section{Participants}

We recruited 60 participants for an experiment in decision making via posters at an Israeli university. Participants were promised a base payment of 35 NIS (about \$8) and an opportunity to earn more.

\section{Procedure}

Upon their arrival, participants were randomly assigned to one of two adjacent rooms. As in the pilot study, experimenters made an effort to convey that participants in the two rooms would complete the experiment in parallel. In fact, the experimenters waited until both rooms had an equal number of participants, in this case 30 .

The experiment included two stages. In the first stage, participants were exposed to the envy manipulation we used in the pilot study. In the second, participants made ultimatum game decisions.

Stage 1 - manipulation. Before beginning the actual experiment, participants were told that they and another group of participants, currently sitting in a different room, would participate in a study about interpersonal decision making. They were then told the following:

Before we begin the actual experiment each of you will be asked to write a short description of yourself (by answering a few focused questions) and to complete a 
personality measure questionnaire. After writing the description and completing the personality measure, you will be paired with someone from the other room and read his/her self-description.

Participants then completed a background information survey. We used the same version of the personality survey as we used in the pilot study, and gave it to participants as a filler task to complete while experimenters outside the lab tailored the envy manipulation materials to match participants in terms of gender, age, and field of study. Each participant then read background information about their purported "counterpart." Unlike the pilot study, participants in this experiment did not answer questions about their feelings of envy. We were concerned that including these questions might focus participants on their feelings of envy and make the true purpose the experiment apparent.

Stage 2: Ultimatum game. After collecting the first set of materials, experimenters announced the beginning of the second stage of the experiment, and handed out a new set of instructions. In these instructions participants were told:

In this research, we are studying interpersonal decision making between people with different levels of acquaintance. As a result, some of you will be matched with someone new that you do not know anything about, and some of you will be matched with the same person whose bio info you have just read.

Participants were told that their personal instructions would inform them which condition they were in (known or unknown counterpart). The instructions also included the following detailed explanation of the rules of the game:

One of you will be Player 1, and one of you will be Player 2. The two of you will make a decision about how to divide a sum of money. Player 1 will receive an amount of money and will make an offer to Player 2 about how to divide it. Player 2 will then decide whether to accept or to reject Player 1's offer. If Player 2 accepts the offer, the money will 
be split between the two of you according to Player 1's proposal. If Player 2 rejects the offer, neither of you will receive any money. You will be paid at the end of this experiment based upon the decisions you and your partner make.

In fact, all participants were assigned the role of Player 1 (i.e., Proposer), and all were informed that they were paired with a "known" counterpart, the counterpart whose description they had just read. Participants were also informed that while they know information about their counterpart, their counterpart does not know who they are or whether or not they are paired with the same person as before. We used these directions to provide participants with a sense of anonymity and to obfuscate the link between our envy induction and our measure of deception.

Participants were informed that all Player 2 knows about the sum of money that Player 1 has to divide is that the amount ranges between 10 NIS and 80 NIS, with any number within that range equally likely. Participants were told that they (as Player 1) will receive a note in a sealed envelope, indicating what the actual sum is (a number between 10 NIS and 80 NIS), and that upon receiving this information they will be asked to send an offer to Player 2 that includes: (a) Giving Player 2 information about the sum of money to be divided; (b) Making an offer to Player 2.

Before receiving information about the pie size and making decisions, participants were given comprehension-check questions to assess their understanding of their role, their treatment condition (with whom they were paired), the rules of the game, and their notion of the research purpose.

Experimenters then gave each participant 3 envelopes. The first included a note specifying the actual sum of money to be divided. In all cases, participants were given the same amount, 60 NIS (about \$14 USD). The second envelope included a form that asked participants to provide their counterpart with information about the size of the pie. The third envelope included a form that asked participants to specify their offer. Participants filled out the forms from the second and third envelopes, sealed the envelopes, and handed them to the experimenter. To give participants 
a sense that the true sum of money they had to divide was private information, we instructed participants to keep the first envelope (that indicated the true pie size) until the conclusion of the study. We told participants that at the conclusion of the experiment they would return the first envelope to a separate experimenter who would pay them based upon their offer, their counterpart's response, and the true pie size. Participants then completed a few final comprehension-check questions.

We added a final stage merely to complete the ultimatum game and determine payments. In this stage, participants in both groups were told that they would play a second ultimatum game in a different role. We told participants in advance that only one of the participants in this second game would be randomly selected and anonymously paid according to the outcome of this game. We used the Player 2 decisions from this stage to calculate payments for the first game.

We then debriefed participants, explained the importance of initially concealing the true purpose of the experiment and of using the manipulated background information surveys, and provided contact information for any further inquiries. Finally, we paid each participant in private. By design, during the payment stage, experimenters did not know whether the participant had or had not lied about the pie size (they only knew the pie size, the amount offered, and whether or not the offer was accepted).

\section{Results}

Of the 60 initial participants, we had to exclude four who failed the comprehension checks and three who were not students. When completing the background information surveys, the three non-students raised their hands and asked how to complete the questions that were irrelevant to them (e.g., about their studies). Unfortunately, these participants were not only unable to complete the background information materials, but were also unable to receive the matching envy induction. As a result, we report results for the 53 remaining participants: 26 in the low envy condition (14 male and 12 female) and 27 in the high envy condition (14 male and 13 female). 
In this study, we did not ask participants to complete questions about their feelings of envy. We were concerned that asking these questions might make the envy manipulation salient and highlight the purpose of the study. Notably, in response to open-ended questions about the objectives of the study, no participants identified any issues related to envy.

To test our thesis that participants would deceive high achieving (envied) counterparts more than they would deceive average (non-envied) counterparts, we examined deception regarding the size of the pie. For each participant, we measured the difference between the actual pie size (amount of 60) and the claimed pie size (the amount the participant reported s/he received). We performed a factorial ANOVA with gender and condition as between-subject independent variables and magnitude of deception as dependent variable. We depict these results in Figure 3. Supporting our thesis, we found a significant main effect for condition $\left(F_{1,49}=4.02\right.$, $\mathrm{p}<.05, \eta^{2}=.08$ ); the magnitude of deception in the high envy condition was significantly larger than in the low envy condition $(15.4, \mathrm{sd}=15$ versus $7.8, \mathrm{sd}=11$ respectively). We found no significant main or interaction effects for gender ( $p$ 's $>.3)$. In subsequent analyses, we collapsed data across the gender conditions.

The difference in deception across envy conditions could be due to differences in the percentage of participants who engaged in deception, differences in the magnitude of deception (i.e., the extent to which participants who did engage in deception misrepresented the pie size), or both. To explore these differences, we conducted two sets of analyses. First, we compared the proportion of participants who lied about the pie size across the envy conditions. A greater percentage of participants lied about the pie size in the high envy condition than in the low envy condition, $61.5 \%$ versus $33.3 \%$, Chi-square $(1)=4.23, \mathrm{p}<.05$. Second, for participants that did lie, we compared the magnitude by which they lied. Across conditions, participants who used deception, lied by similar amounts. The 10 participants in the low envy condition misrepresented the pie size by an average of $20.2(\mathrm{sd}=9.2)$, and the 18 participants in the high envy condition 
misrepresented the pie size by an average of $23(\mathrm{sd}=13) ; \mathrm{t}_{26}<1$. Taken together, we found that envy increased the likelihood that participants would lie, rather that the magnitude by which they lied.

We next examined the relationship between the use of deception and the amount participants offered. We conducted a factorial ANOVA for the amount participants offered as a function of the condition (low versus high envy) and whether or not they engaged in deception (did lie versus did not lie). We found a significant effect for engaging in deception $\left(\mathrm{F}_{1,49}=18.45\right.$, $\mathrm{p}<.0001, \eta^{2}=.27$ ), but no significant main or interaction effects for condition ( $\left.p^{\prime} s>.8\right)$. Across conditions, participants who lied about the pie size offered significantly less than did participants who did not lie, $19.0(\mathrm{sd}=7.2)$ versus 27.1 , $(\mathrm{sd}=5.2)$, respectively.

\section{Study 2 Discussion}

In the present study, we induced envy by providing participants with general unfavorable social comparison information. In our pilot study, we found that these comparisons significantly influenced feelings of envy. In our main study, we used monetary stakes and found that these unfavorable social comparisons prompted individuals to engage in deception.

This study extends our investigation in two important ways. First, we demonstrate that envy can trigger deception behavior in a negotiation context. Second, we show that envy can be triggered by merely providing individuals with general background information about a counterpart that triggers an unfavorable social comparison.

In our study, we found that envy promoted deception by increasing the likelihood that participants would engage in deception, rather than by increasing the magnitude by which participants lied. That is, while participants were more likely to lie to a high achiever than they were to a moderate achiever, deceivers across both conditions lied by similar amounts. This lack of a difference in deception amount, however, may be an artifact of our methods. The range of 
values, 10 to 80 , was common information, and participants were constrained by the extent to which they could credibly misrepresent the pie size.

Across conditions, participants offered about half of the claimed pie size. Participants who lied about the pie size offered $45 \%$ of their claimed pie size, while participants who did not lie about the pie size offered $48 \%$. The similarity in offers is also likely an artifact of our methods. Prior work has found that in ultimatum games people generally offer the focal amount of $50 \%$ of the pie (Guth et al., 1982; Roth, Prasnikar, Zamir, \& Okuno-Fujiwara, 1991; Thaler, 1988).

\section{GENERAL DISCUSSION}

In this work, we describe the influence of envy on the use of deception in interpersonal settings such as negotiations. We find that envy increases not only self-reported intentions to use deception, but also its actual use in an experiment with monetary stakes.

Our findings add to the growing body of literature on the pervasive influence of emotions on judgments, decision making, and behavior (e.g., Forgas \& George, 2001; Guth, et al., 1982; Gneezy, 2004; Loewenstein et al., 1989; Allred et al., 1997). In the specific domain of negotiations, this research contributes by identifying a relatively under-studied discrete emotion, which results from unfavorable social comparisons and can have important impacts on negotiator behavior.

Ultimately, our results have important implications for theoretical models of ethical decision making. Theoretical models of deception, including Lewicki's (Lewicki, 1983; Lewicki et al., 2003) and others (e.g., Alingham \& Sandmo, 1972; Jones, 1995; Jones \& Ryan, 1997, 2001; Trevino, 1986), have largely ignored the role of emotions as potential triggers of unethical behavior. Our results demonstrate that this is an important omission.

Consistent with a cost-benefit framework of deception (e.g., Lewicki 1983; Lewicki et al., 2003), we find that envy promotes the use of deception by both increasing its psychological 
benefits, by inducing schadenfreude, and reducing its psychological costs by increasing belittling and assisting self justification.

Across our studies, we found that envy is easy to induce. In our first study, we induced envy by describing a discrete unfavorable outcome from a workplace competition. We found that envy in this case did not require perceived violations of procedural fairness. In our second study, we induced envy by providing participants with general unfavorable social comparison information. Although our studies focused on the influence of envy with respect to negotiator behavior, people frequently experience both unfavorable outcomes and unfavorable social comparisons. As a result, envy driven deception may be triggered across, and have broad implications for, a wide range of social interactions. For example, although little research has considered workplace envy, we postulate that envy is likely to pose an important workplace problem (Mouly \& Sankaran, 2002; Vecchio, 1995, 2000). In the workplace, formal competitive systems, such as performance reviews and promotions, as well as other social interactions, such as negotiations, are likely to cue social comparisons. When coworkers engage in upward social comparisons they are likely to experience envy. Prescriptively, several managerial actions might be worth considering in an attempt to curtail envy and its harmful consequences. Managers can, for example, modify their reward systems to make them less competitive. Our results suggest that increasing the likelihood that competitive reward systems will be viewed as fair may not be sufficient.

Our research has additional prescriptive implications for issues related to impression management. Impression management characterizes efforts individuals undertake to influence how others' perceive them. While prior work has assumed that impression management strategies such as highlighting one's own out-performance are beneficial (e.g., Rosenfeld, Giacalone, \& Riordan, 2002), our work demonstrates that such strategies can trigger harmful consequences by inducing envy. In fact, in many cases, individuals are likely to be well served by being modest 
rather than self-promoting about their status and past good fortune. Future work should reexamine impression management strategies and consider both the benefits and costs of impression management.

In the specific context of negotiation, negotiators may be able to take a number of actions both to curtail envy and to limit envy's harmful consequences. In some cases, past accomplishments are beneficial for negotiators. Specifically, if past achievements afford negotiators advantageous sources of power (e.g., positional power or referent power; Yukl \& Falbe, 1991; Greenberg \& Baron, 2003), they can negotiate more assertively and attain better outcomes (Mannix, 1993; Pinkley, Neale, \& Bennett, 1994; Thompson, 2001; Lewicki et al., 2003). The present results suggest, however, that past successes may sometimes be a liability rather than an asset. We demonstrate an adverse consequence of past success, being envied. Consequently, while prior work suggests that negotiators should be modest about their surplus after completing a negotiation (e.g., Novemsky \& Schweitzer, 2004), results from this work suggest that individuals should be modest before and during a negotiation about issues unrelated to the negotiation itself.

This issue is related to the construct of emotional intelligence. Emotional intelligence is the capacity to perceive and be aware of emotions, assimilate emotion-related feelings, understand the information of these emotions, and manage emotions effectively (Mayer, Caruso \& Salovey, 1999). As a result, emotional intelligence is likely to play an important role in the management and enactment of envy. From the envied person's perspective, greater emotional intelligence may enable an individual to be less likely to trigger envy, more likely to detect envy, and more likely to diffuse or mitigate the harmful effects of envy. From the envious person's perspective, emotional intelligence is relevant for becoming aware of possessing this emotion and effectively managing its enactment in a way that might lessen its potentially harming consequences. 


\section{Limitations and future research}

Before concluding we note limitations inherent in the present work and suggest directions for future research. First, although in this research we provide initial insight into psychological processes that mediate the link between envy and deception, future work is warranted to further explore the mechanics of this relationship. Possible moderators of the envy-deception relationship include constructs such as perceived deservingness, self-esteem, and perceived self-competence. Prior work has found that negative attitudes toward high achievers occur more intensely when individuals believe that envied others do not deserve their rewards (e.g., Smith, 1991; Smith et al., 1994; Feather \& Sherman, 2002) and when individuals themselves have low rather than high selfesteem (e.g., Feather, 1989, 1991). A related avenue for future research is the role of dispositional envy (Smith et al., 1999). Some individuals are prone to feeling envy more acutely than are others. In the present research, we did not examine or control for dispositional envy.

Second, while in the present research we focused on the envious target, future work should also consider the perspective of the envied target. This work should for example investigate the extent to which people recognize that their accomplishments induce envy in others. Envy is a self-sanction emotion (Vecchio, 1995; Anderson, 1968; Silver and Sabini, 1978), and many people who experience envy refrain from verbalizing their true feelings. As a result, individuals aiming to manage impressions or simply build credibility by highlighting their past successes may fail to recognize the envy they trigger in others and fail to anticipate its harmful consequences. In celebrating their past successes, people may ultimately make future success more elusive.

Third, from a methodological point of view, in Study 1 we used a hypothetical scenario and in Study 2 we used anonymous counterparts in an ultimatum game. As a result, we need to be cautious about generalizing our results to real life negotiation situations where parties interact 
beyond a single ultimatum offer, when identities are known, when long term relationships might be involved, and when stakes may be high. Our studies did not involve the social and long-term economic costs that deception in real life negotiations may entail. Notwithstanding, we maintain that because both envy and deception are socially undesirable, participants may have been reluctant to admit to feeling envy and engaging in deception in our studies. Hence, social desirability considerations of our participants may have resulted in underestimation rather than overestimation of their prevalence.

\section{Conclusion}

Results from this work describe the influence of envy on the decision to use deception. We find that people are more likely to lie to an envied counterpart than they are to lie to a nonenvied counterpart. These findings add to the growing body of literature on the pervasive influence of emotions in negotiations. In particular, they highlight the potential role of an understudied discrete emotion, envy, which is likely to be triggered in negotiation settings where social comparisons are common. Our results also have implications for theoretical models of ethical decision making. In particular, they point to the importance of attending to the role of emotions as potential antecedents of unethical behavior, which has largely been ignored. Since receiving unfavorable competition outcomes and unfavorable social comparison information are frequent experiences in many settings, we maintain that the envy driven deception we find in the domain of negotiations is likely to be facilitated across, and have implications for, a broad range of social interactions. 


\section{REFERENCES}

Alingham, M. G., \& Sandmo, A. (1972). Income tax evasion: A theoretical analysis. Journal of Public Economics, 1, 323-338.

Allred, K. G., Mallozzi, J. S., Matsui, F., \& Raia, C. P. (1997). The influence of anger and compassion on negotiation performance. Organizational Behavior and Human Decision Processes, 70(3), 175-187.

Anderson, N.H. (1968). Likableness ratings of 555 personality-trait words. Journal of Personality and Social Psychology, 9, 272-279.

Baron, R. A. (1990). Environmentally induced positive affect: Its impact on self-efficacy, task performance, negotiation, and conflict. Journal of Applied Social Psychology, 20 (5, Pt 2), $368-384$.

Baron, R. M., \& Kenny, D. A. (1986). The moderator-mediator variable distinction in social psychological research: Conceptual, strategic, and statistical considerations. Journal of Personality and Social Psychology, 51(6), 1173-1182.

Barry, B. (1999). The tactical use of emotion in negotiation. In R. J. Lewicki (Ed), et-al., R. J. Bies (Ed), Research in Negotiation in Organizations, Vol. 7. (pp.93-121). US: Elsevier Science.

Barry, B., \& Oliver, R. L. (1996). Affect in dyadic negotiation: A model and propositions. Organizational Behavior and Human Decision Processes, 67(2), 127-143.

Bazerman, M. H., Curhan, J. R., Moore, D. A.,\& Valley, K. L. (2000). Negotiation. Annual Review of Psychology, 51, 279-314.

Bazerman, M. H. \& Neale, M. A. (1992). Negotiating rationally. N.Y.: The Free Press. Brigham, N.L., Kelso K.A., Jackson M.A., \& Smith, R. H. (1997). The roles of invidious comparisons and deservingness in sympathy and Schadenfreude. Basic and Applied Social Psychology 19 (3), 363-380. 
Buller, D. B., Burgoon, J. K. (1998). Emotional expression in the deception process. In L. K. Guerrero, P. A. Andersen(eds.), Handbook of communication and emotion: Research, theory, applications, and contexts. (pp.381-402). San Diego, CA, US: Academic Press.

Carnevale, P. J., \& Isen A. (1986). The influence of positive affect and visual access on the discovery of integrative solutions in bilateral negotiations. Organizational Behavior and Human Decision Processes, 37, 1-13.

Connolly, T., \& Ordonez, L. D. (2000). Regret and responsibility: A reply to Zeelenberg et al. (1998). Organizational Behavior and Human Decision Processes, 81(1), 132-142.

Croson, R., Boles, T., \& Murnighan, J. K. (2003). Cheap talk in bargaining experiments: Lying and threats in ultimatum games. Journal of Economic Behavior and Organization, 51 (2), 143-159.

Duffy, M. K., \& Shaw, J. D. (2000). The Salieri syndrome: Consequences of envy in groups. Small Group Research, 31(1), 3-23.

Ekman, P. (2003). Emotions revealed: Recognizing faces and feelings to improve communication and emotional life. New York: Times Books/Henry Holt and Co.

Feather, N. T. (1991). Attitudes towards the high achiever: Effects of perceiver's own level of competence. Australian Journal of Psychology, 43(3), 121-124.

Feather N. T. (1989). Attitudes towards the high achiever: The fall of the tall poppy. Australian Journal of Psychology, 41(3), 239-267.

Feather, N. T., \& Sherman, R. (2002). Envy, resentment, Schadenfreude, and sympathy: Reactions to deserved and underserved achievement and subsequent failure. Personality and Social Psychology Bulletin, 28(7), 953-961.

Forgas, J. P. (1998). On feeling good and getting your way: mood effects of negotiator cognition and bargaining strategies. Journal of Personality and Social Psychology, 74, 566-577. 
Forgas, J. P., \& George, J. M. (2001). Affective influences on judgments and behavior in organizations: An information processing perspective. Organizational Behavior and Human Decision Processes, 86 (1), 3-34.

Frank R. H. (2002). Smiles, lies, and emotion. In Abel, Millicent H (Ed), An empirical reflection on the smile. (pp.15-43). Lewiston, NY, US: Edwin Mellen Press.

Frank, R. H. (1988). Passions within reason: The strategic role of the emotions. New York: W. W. Norton \& Co.

Frank, R. H., \& Ekman, P. (1997). The ability to detect deceit generalizes across different types of high-stake lies. Journal of Personality and Social Psychology, 72(6), 1429-1439.

Friedman, R., Anderson, C., Brett, J., Olekalns, M., Goates, N., \& Lisco, C. C. (2004). The positive and negative effects of anger on dispute resolution: Evidence from electronically mediated disputes. Journal of Applied Psychology, 89(2), 369-376.

Gaudine, A., \& Thorne, L. (2001). Emotion and ethical decision-making in organizations. Journal of Business Ethics, 31, 175-187.

Gneezy, U. (2004). Deception: The role of consequences. Unpublished Manuscript.

Greenberg, G., \& Baron, R.A. (2003). Behavior in organizations ( $8^{\text {th }}$ edition). Upper Saddle River: Prentice-Hall.

Grover, S. L. (1993). Lying, deceit, and subterfuge: A model of dishonesty in the workplace. Organizational Science, 4, 478-495.

Guth, W., Schmittberger, R., \& Schwarze, B. (1982). An experimental analysis of ultimatum bargaining. Journal of Economic Behavior and Organization, 3, 367-388.

Heider, F. (1958). The psychology of interpersonal relations. Hillsdale, NJ, England: Lawrence Erlbaum Associates.

Holmstrom, B. (1979). Moral hazard and observability. Bell Journal of Economics, 10, 74-91. 
Isen, A. M., Daubman, K. A., \& Nowicki, G. P. (1987). Positive affect facilitates creative problem solving. Journal of Personality and Social Psychology, 52 (6), 1122-1131.

Jones, T. M. (1995). Instrumental stakeholder theory: A synthesis of ethics and economics. The Academy of Management Review, 20(2), 404-436.

Jones, T. M., \& Ryan, L. V. (2001). The effect of organizational forces on individual morality: Judgment, moral approbation, and behavior. In Moberg, Dennis (Ed), et-al. Dienhart, John (Ed), The next phase of business ethics: Integrating psychology and ethics. (pp.285-300). US: Elsevier Science/JAI Press.

Jones, T. M., \& Ryan, L. V. (1997). The link between ethical judgment and action in organizations: A moral approbation approach. Organization Science, 8(6), 663-680.

Lewicki, R. J. (1983). Lying and deception: A behavioral model. In M. H. Bazerman \& R. J. Lewicki (Eds.), Negotiating in organizations (pp. 68-90). Beverly Hills, CA: Sage.

Lewicki, R. J., Barry, B., Saunders, D. M., \& Minton, J. W. (2003). Negotiation (4 ${ }^{\text {th }}$ edition). New York: McGraw-Hill.

Lewicki, R. \&. Robinson, R. (1998). Ethical and unethical bargaining tactics: An empirical study. Journal of Business Ethics. 17, 665-682.

Lewicki, R. J., Saunders, D. M., \& Minton, J. W. (1999). Negotiation: Readings, exercises, and cases ( $3^{\text {rd }}$ edition). Boston, MA: McGraw-Hill.

Loewenstein, G. F., Thompson, L., \& Bazerman, M. H. (1989). Social utility and decision making in interpersonal contexts. Journal of Personality and Social Psychology, 57(3), 426-441.

Mannix, E. (1993). Organizations as resource dilemmas: The effects of power balance on coalition formation in small groups. Organizational Behavior and Human Decision Processes, 55, 1-22.

Mayer, J. D., Caruso, D. R., \& Salovey, P. (1999). Emotional intelligence meets traditional standards for an intelligence. Intelligence, 27(4), 267-298. 
Morris, M. W., \& Keltner, D. (2000). How emotions work: The social functions of emotional expression in negotiations. Research in Organizational Behavior, 22, 1-50.

Mouly, V. S., \& Sunkaran, J. K. (2002). The enactment of envy within organizations: Insights from a New Zealand academic department. Journal of Applied Behavioral Sciences, 38(1), $36-56$.

Murnighan, J. K. (1991). The dynamics of bargaining games. Englewood Cliffs, NJ: Prentice Hall.

Novemsky, N. \& Schweitzer, M. (2004). What makes negotiators happy? The differential effects of internal and external social comparisons on negotiator satisfaction. Organizational Behavior and Human Decision Processes, 95, 186-197.

Parks, C. D., Rumble, A. C., \& Posey, D. C.(2002). Effects of envy on reciprocation in a social dilemma. Personality and Social Psychology Bulletin, 28(4), 509-520.

Parrot, W. G., \& Smith, R. H. (1993). Distinguishing the experiences of envy and Jealousy. Journal of Personality and Social Psychology, 64(6), 906-920.

Pillutla, M. M., \& Murnighan, J. K. (1996). Unfairness, anger, and spite: Emotional rejections of ultimatum offers. Organizational Behavior and Human Decision Processes, 68 (3), 208224.

Pinkley, R. L., Neale M. A., \& Bennett, R. J. (1994). The impact of alternatives to settlement in dyadic negotiation. Organizational Behavior and Human Decision Processes, 57(1), 97116.

Robinson, R., Lewicki, R. J., \& Donahue, E. (2000). Extending and testing a five factor model of ethical and unethical bargaining tactics: Introducing the SINS scale. Journal of Organizational Behavior, 21, 649-664.

Rosenfeld, P., Giacalone, R. A., \& Riordan, C. A. (2002). Impression management: Building and enhancing reputations at work. London: Thompson learning. 
Roth, A. E., Prasnikar, V., \& Okuno-Fujiwara, M. (1991). Bargaining and market behavior in Jerusalem, Ljubljana, Pittsburgh and Tokyo - An experimental study. American Economic Review, 81(5), 1068-1095.

Salovey, P., \& Rodin, J. (1984). Some antecedents and consequences of social comparison jealousy. Journal of Personality and Social Psychology, 47(4), 780-792.

Schweitzer, M. E.,\& Croson, R. (1999). Curtailing deception: The impact of direct questions on lies and omissions. International Journal of Conflict Management, 10(3), 225-248.

Schweitzer, M. E., \& Hsee, C. (2002). Stretching the truth: Elastic justification and motivated communication of uncertain information. The Journal of Risk and Uncertainty, 25(2), $185-201$.

Schweitzer, M. E., Ordonez, L., \& Douma, B. (2004). Goal setting as a motivator of unethical behavior. The Academy of Management Journal, 47(3), 422-432.

Silver, M., \& Sabini, J. P. (1978). The perception of envy. Social Psychology, 41(2), 105-111.

Smith, R. H. (1991). Envy and the sense of injustice. In P. Salovey (Ed.). Psychological perspectives on jealousy and envy (pp. 79-99). New York: Guilford.

Smith, R. H., Parrott, W. G., Diener, E.F., Hoyle, R. H., \& Kim, S. H. (1999). Dispositional envy. Personality and Social Psychology Bulletin, 25(8), 1007-1020.

Smith, R. H., Parrott, W. G., Ozer, D., Moniz, A. (1994). Subjective injustice and inferiority as predictors of hostile and depressive feelings in envy. Personality and Social Psychology Bulletin 20(6), 705-711.

Smith, R. H., Turner, T. J., Garoznik, R., Leach, C. W., Urch-Druskat, V., \& Weston, C. M. (1996). Envy and schadenfreude. Personality and Social Psychology Bulletin, 22(2), 158168.

Sobel, M. E. (1982). Asymptotic intervals for indirect effects in structural equations models. In S. Leinhart (Ed.), Sociological methodology 1982 (pp.290-312). San Francisco: Jossey-Bass. 
Straub, P. J., \& Murnighan, J. K. (1995). An experimental investigation of ultimatum games information, fairness, expectations and lowest acceptable offers. Journal of Economic Behavior and Organization, 27(3), 345-364.

Tenbrunsel, A. E., \& Messick, D. M. (2004). Ethical fading: The role of self deception in unethical behavior. Social Justice Research, 17(2), 223-236.

Tenbrunsel, A. E., \& Messick, D. M. (2001). Power asymmetries and the ethical atmosphere in negotiations. In Messick, David M (Ed), et-al. Darley, John M (Ed), Social influences on ethical behavior in organizations. (pp.201-216). Mahwah, NJ, US: Lawrence Erlbaum Associates.

Tesser, A., \& Collins, J. E. (1988). Emotion in social reflection and comparison situations: Intuitive, systematic, and exploratory approaches. Journal of Personality and Social Psychology, 55(5), 695-709.

Thaler, R. H. (1988). Anomalies - The ultimatum game. Journal of Economic Perspectives, 2(4), 195-206.

Thompson, L. L.(2001). The mind and heart of the negotiator. Upper Saddle River, NJ: Prentice Hall.

Thompson, L., Nadler, J., \& Kim, P. (1999). Some like it hot: The case of the emotional negotiator. In L. Thompson, J. Levine and D. Messick (Eds.), Shared cognition in organizations: The management of knowledge (pp. 139-162). Mahwah, NJ: Erlbaum.

Trevino, L. K. (1986). Ethical decision making in organizations: A person-situation interactionist model. Academy of Management Review, 11 (3), 601-617.

Van Kleef, G. A., De Dreu, C. K. W., \& Manstead, A. S. R. (2004a) The interpersonal effects of anger and happiness in negotiations. Journal of Personality and Social Psychology. 86(1), $57-76$. 
Van Kleef, G. A., De Dreu, C. K. W., \& Manstead, A. S. R. (2004b). The interpersonal effects of anger and happiness in negotiations: A motivated information processing approach. Journal of Personality and Social Psychology, 87(4), 510-528.

Vecchio, R. P. (2000). Negative emotion in the workplace: Employee jealousy and envy. International Journal of Stress Management, 7(3), 161-179.

Vecchio, R. P. (1995). It's not easy being green: Jealousy and envy in the workplace. In G.R. Ferris (Ed.), Research in Personnel and Human Resources Management, 13 (pp-201-244). Greenwich, CT: JAI Press.

Yukl, G., \& Falbe, C. M. (1991). Importance of different power sources in downward and lateral relations. Journal of Applied Psychology, 76(3), 416-423. 
Figure 1: Study 1 - SINS score as a function of condition and gender

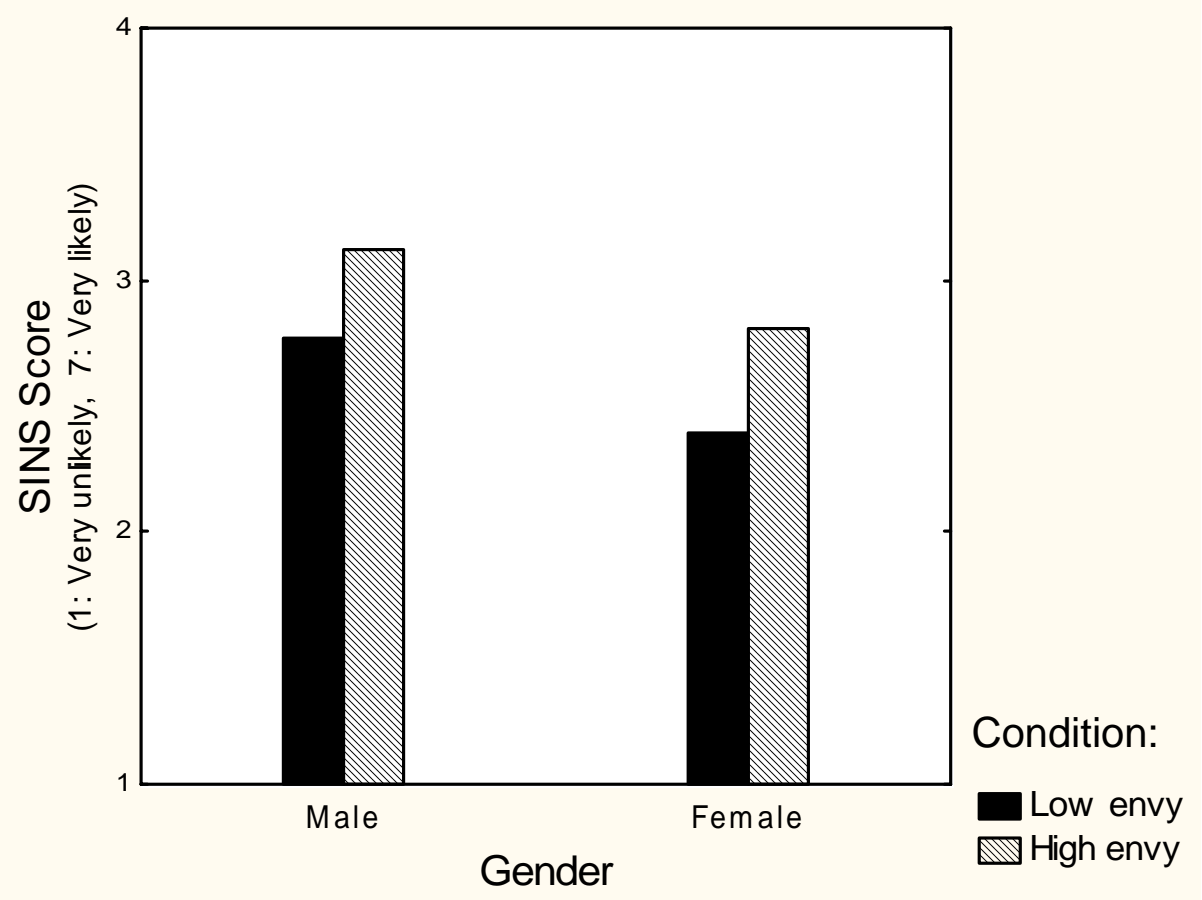


Figure 2: Study 1 -Mediating Analysis

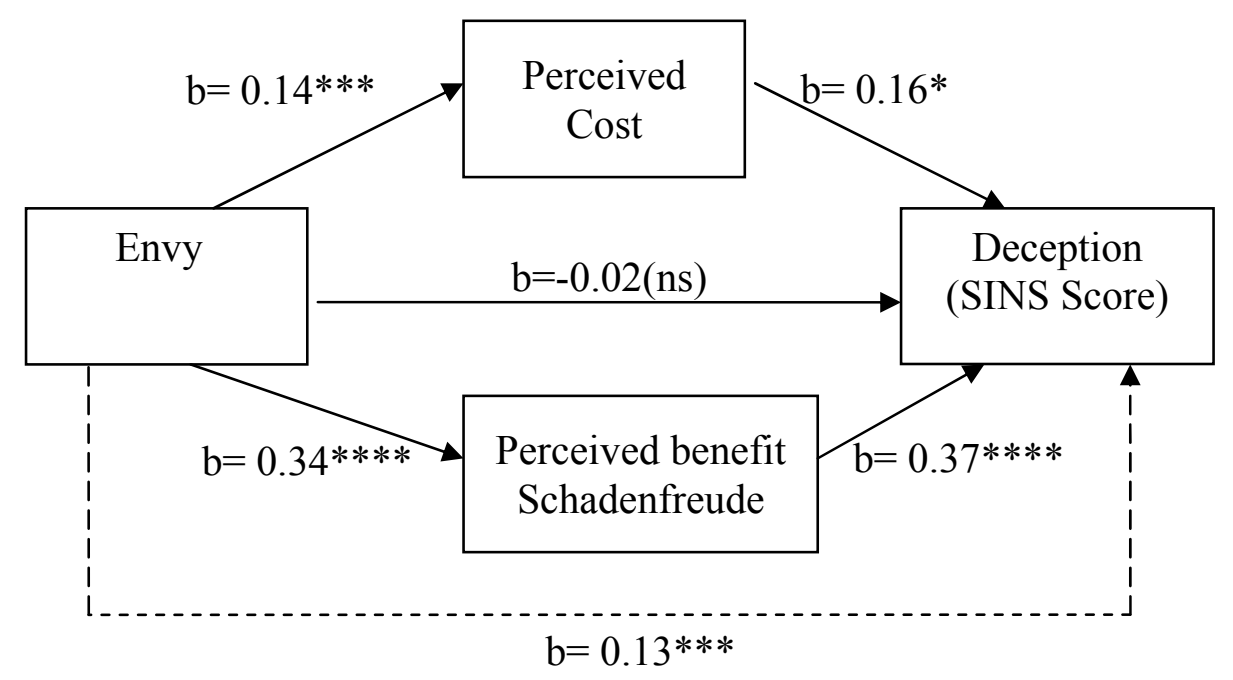

$* \quad=$ significant at $\mathrm{p}<.05$

$* *=$ significant at $\mathrm{p}<.01$

$* * *$ = significant at $\mathrm{p}<.001$

$* * * *=$ significant at $<.0001$ 
Figure 3: Study 2 - Deception as a function of condition and gender

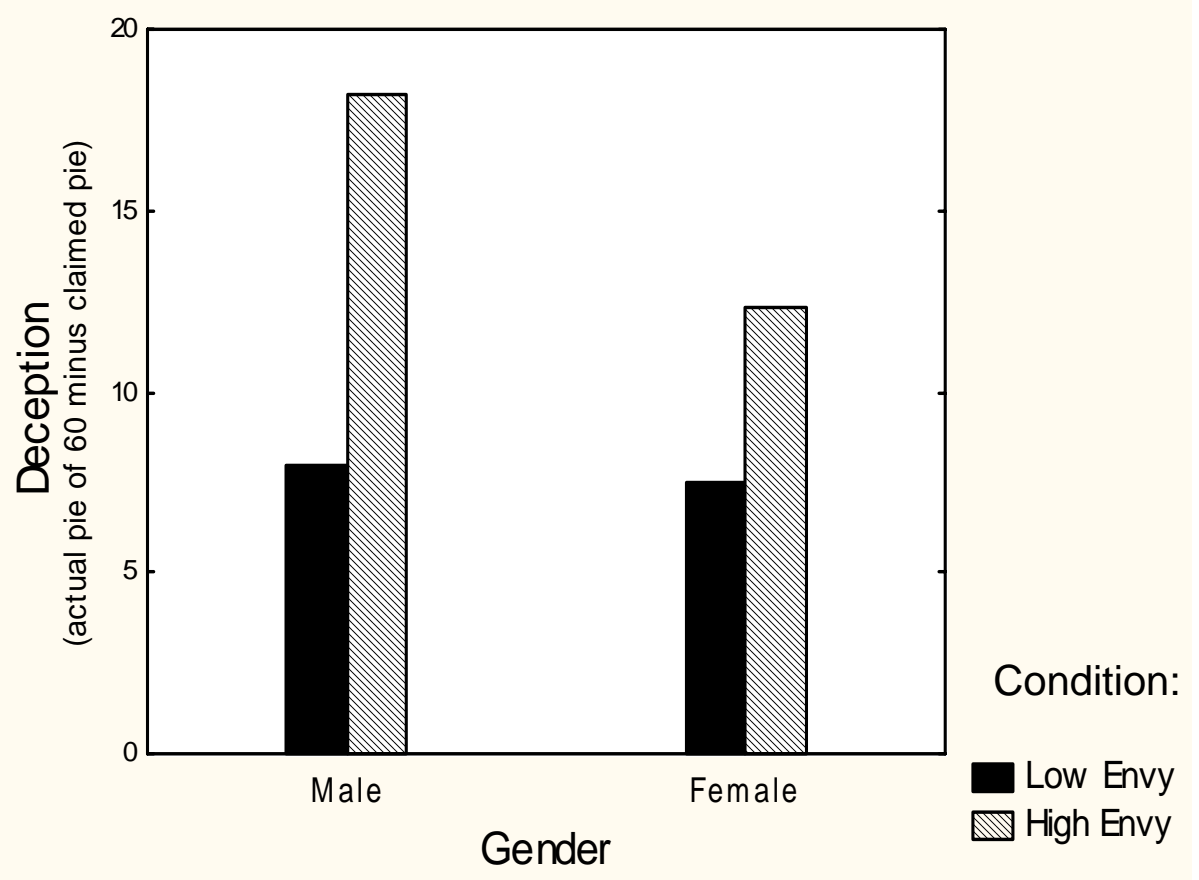


Table 1: Study 1 - Correlations between independent variables

\begin{tabular}{|l|c|c|c|}
\hline & Envy & Perceived Cost & $\begin{array}{c}\text { Perceived Benefit } \\
\text { (Schadenfreude) }\end{array}$ \\
\hline Envy & 1 & 1 & \\
\hline Perceived Cost & $.29^{* *}$ & & 1 \\
\hline $\begin{array}{l}\text { Perceived Benefit } \\
\text { (schadenfreude) }\end{array}$ & $.51^{* *}$ & $.56^{* *}$ & \\
\hline
\end{tabular}

$* *=$ significant at $\mathrm{p}<0.01$ 
Table 2: Study 1 - Results of a multiple regression for predicting SINS from envy, perceived costs and perceived benefits (schadenfreude)

\begin{tabular}{|l|c|c|c|c|c|c|c|}
\hline & \multicolumn{2}{|c|}{$\begin{array}{c}\text { Unstandardized } \\
\text { Coefficients }\end{array}$} & $\begin{array}{c}\text { Standardized } \\
\text { Coefficients }\end{array}$ & \multirow{2}{*}{$\mathbf{N}$} & \multicolumn{2}{c|}{$\begin{array}{c}\text { Collinearity } \\
\text { Statistics }\end{array}$} \\
\cline { 1 - 4 } Effect & $\mathbf{B}$ & $\begin{array}{c}\text { Std. } \\
\text { Error }\end{array}$ & Beta & $\mathbf{P}$ & Tolerance & VIF \\
\hline Constant & 1.54 & .18 & & 8.50 & .000 & & \\
\hline Envy & -.02 & .04 & -.05 & -.6 & .549 & .74 & 1.35 \\
\hline Perceived Cost & .16 & .08 & .16 & 2.08 & .039 & .68 & 1.47 \\
\hline $\begin{array}{l}\text { Perceived Benefit } \\
\text { (Schadenfreude) }\end{array}$ & .37 & .06 & .50 & 5.82 & .000 & .55 & 1.81 \\
\hline
\end{tabular}

R: 0.59, R Square: 0.344, Adjusted R square: 0.33, Standard error of estimate: 0.83

Analysis Of Variance:

$\begin{array}{lcclcc}\text { Source } & \text { Sum-of-Squares } & \text { df } & \text { Mean-Square } & \text { F-ratio } & \text { P } \\ \text { Regression } & 57.53 & 3 & 19.18 & 28 & 0.000 \\ \text { Residual } & 109.68 & 160 & 0.69 & & \end{array}$




\section{Appendix 1}

\section{$\underline{\text { Study } 1 \text { - Deception Measure (adapted SINS Scale) }}$}

This questionnaire includes a list of tactics that negotiators sometimes use. For each tactic, please rate the likelihood that you would use it during your negotiations with Dan from "not at all likely" (score of 1) to "very likely" (score of 7). Circle a number.

1. Promise that good things will happen to Dan if he gives you what you want, even if you know that you can't (or won't) deliver these things when his cooperation is obtained.

2. Intentionally misrepresent information to Dan in order to strengthen your negotiation arguments or positions.

3. Make an opening demand that is far greater than what you really hope to settle for.

4. Convey a false impression that you are in absolutely no hurry to come to a negotiated agreement, thereby trying to put time pressure on Dan to concede quickly.

5. In return for concessions from Dan now, promise to make future concessions which you know you will not follow through on.

6. Deny the validity of information which Dan has that weakens your negotiating position, even though that information is true and valid.

7. Make an opening demand so extreme that it seriously undermines Dan's confidence in his ability to negotiate a satisfactory settlement.

8. Guarantee that the rest of the managers and employees in your department, whom you represent in this negotiation, will uphold the settlement that you reach, although you know that they will likely violate the agreement later. 


\section{Appendix 2}

$\underline{\text { Study } 1 \text { - Items included in the questionnaire for measuring potential mediating mechanisms }}$

The questionnaire included the following items with seven point scales:

a) Perceived cost and justifiability of deception:

(1) "It is justifiable for me to lie to Dan."

(2) "If I lied to Dan during our negotiation, it would bother me a lot afterward." (r)

(3) "Dan is probably the type to only look out for himself."

(4) "Dan is the type I would like to avoid spending time with if I can."

(5) "I would bet that Dan has done some brownnosing at work."

b) Feelings of Shaden freude toward the other party - 3 items:

(1) "I want to compliment Dan on the work he has done." (r)

(2) "I would really like to make Dan mad."

(3) "Even if my outcome stayed the same, it would make me happy if Dan did poorly in the negotiation." 